Revista Iberoamericana, Vol. LXXVIII, Núms. 238-239, Enero-Junio 2012, 25-38

\title{
EL VIAJE A MARTE EN LA IMAGINACIÓN ARGENTINA AYER Y HOY: VIAJE MARAVILLOSO DEL SEÑOR NIC-NAC AL PLANETA MARTE DE HOLMBERG Y VIAJE A MARTE DE ZARAMELLA
}

\author{
POR \\ Rachel Haywood Ferreira ${ }^{1}$ \\ Iowa State University
}

El entonces estudiante de medicina Eduardo Ladislao Holmberg (1852-1937) publicó su texto Viaje maravilloso del Señor Nic-Nac en el que se refieren las prodijiosas aventuras de este señor y se daná conocer las instituciones, costumbres y preocupaciones de un mundo desconocido: Fantasía espiritista en el periódico El Nacional en doce entregas entre noviembre de 1875 y febrero de 1876. Al terminar la publicación de la versión en folletín, la imprenta de El Nacional lanzó la obra en forma de un libro de ciento ochentiocho páginas bajo el mismo título. ${ }^{2}$ Más de un siglo después, Juan Pablo Zaramella (1972-) volvió a mandar a un argentino al planeta rojo en su tercer cortometraje de animación en plastilina, Viaje a Marte. Zaramella y su co-guionista Mario Rulloni desarrollaron, filmaron y editaron este corto de dieciséis minutos con un equipo mínimo durante su tiempo libre en un departamento de tres ambientes entre 2002 y 2004. Después de la publicación de Nic-Nac como libro, el texto desapareció durante casi cien años; no se reeditó en su totalidad hasta 2006 y nunca fue traducido. Sin embargo, en las últimas dos décadas el texto ha logrado un reconocimiento general como obra pionera de la ciencia-ficción latinoamericana. Por su parte, en los ocho años que van desde su estreno, Viaje a Marte ha ganado más de cincuenta premios en Latinoamérica, Europa y los Estados Unidos y también en países como Japón, Australia, e Irán. Estos premios han reconocido los méritos de la dirección, la animación, el guión, el sonido, y aún han recibido premios del público, pero ninguno de ellos estuvo relacionado con el ámbito

1 Todas las traducciones del inglés al español en las citas son mías. La cita aparece en el inglés original solamente en los casos en los cuales la formulación de la frase es especialmente importante. Las transcripciones del diálogo de Viaje a Marte son mías; están basadas en la transcripción de Aparisi y otros, pero contienen algunas alteraciones en la puntuación y en la atribución de voces.

2 Frecuentemente "Viaje maravilloso del Señor Nic-Nac al planeta Marte" se da como el título completo de la obra. Éste es el título que encabeza la narración enmarcada que ocupa la mayoría del texto y constituye la crónica de viaje del señor Nic-Nac. Viaje maravilloso del Señor Nic-Nac en el que se refieren... es el título completo de la obra; incluye la narración enmarcada de Nic-Nac y la historia marco, narrada por un "editor", sobre la recepción incial de Nic-Nac a su regreso de Marte. En este ensayo usamos la abreviatura Nic-Nac para referirnos a la obra completa; citamos de la primera edición del libro. 
ni el género de la ciencia-ficción. El corto está disponible con subtítulos en inglés. A diferencia de un largometraje, hay que recurrir a ambientes menos tradicionales para verlo: festivales de cine, clases de español en las universidades norteamericanas y, recientemente, YouTube. ${ }^{3}$

Aunque las dos obras traten del primer viaje del hombre a Marte con un argentino como protagonista, Holmberg y su texto decimonónico no fueron influencias directas -ni indirectas- en Zaramella ni en su película. Pero no buscamos trazar una genealogía explícita entre estas obras ubicadas en los extremos cronológicos de la ciencia-ficción latinoamericana. Nuestro interés presente es usar estos dos viajes fantásticos para discutir algunas de las características del género en América Latina y para examinar el nivel de penetración que la ciencia-ficción ha alcanzado y mantenido en la cultura y la ficción latinoamericanas durante más de un siglo.

A pesar de exhibir viajes espaciales en primer plano, se puede argumentar que estas obras no pertenecen a la ciencia-ficción "de género" [genre science fiction] en el sentido más estricto del término por la temprana fecha de Nic-Nac y las raíces de la trama de Viaje a Marte en una historia "anti-bildungsroman". ${ }^{4}$ Las dos obras también demuestran la tendencia a la hibridez genérica que es históricamente más fuerte en la ciencia-ficción de América Latina. Pero ésto no quiere decir que las obras no puedan ser consideradas parte del género y examinadas a través del lente de la ciencia-ficción. Holmberg y Zaramella-Rulloni son muy conscientes de los tropos y las convenciones de la ciencia-ficción. Los utilizan para expresar la actitud de los argentinos hacia la ciencia y la tecnología, para explorar temas de identidad nacional y del papel de Argentina en el mundo, particularmente la dinámica de sus relaciones con Europa y los Estados Unidos. La ciencia-ficción tiene sus raíces históricas en el Norte, y la sede del género sigue estando en los países del centro. ${ }^{5} \mathrm{Al}$ emplear este género desde un país periférico, nuestros escritores no sólo representan cosmovisiones alternativas a las que predominan en la ciencia-ficción, sino que interrogan los supuestos de la ciencia-ficción del Norte y de la cosmovisión corriente del centro.

\footnotetext{
3 Viaje a Marte es uno de los seis cortometrajes incluidos en el libro de texto para el tercer año universitario de lengua española, Revista: Conversación sin barreras, por Aparisi y otros. De hecho, yo encontré el corto no como investigadora de la ciencia-ficción, sino al enseñar este texto en un curso de conversación en 2007. Viaje a Marte es muy popular con los estudiantes. La versión del corto en YouTube parece haber sido subida por un fan.

4 Al usar los viajes al planeta rojo como eventos catalizadores en la vida de un argentino, la película, en palabras de un crítico norteamericano, "neatly reverses the moral of every disillusioned-boy-becomes-aman story ever told. It’s sort of Capricorn One meets Baron Munchausen in Argentina” (Jessen).

5 Utilizo el término "centro" y la mayúscula en la palabra "Norte” para indicar la región que más impacto ha tenido en las ciencias y en la ciencia-ficción. Los integrantes principales de esta región suelen ser los Estados Unidos, Gran Bretaña, Francia, Alemania y Rusia; generalmente se excluyen España, Portugal e Italia.

Revista Iberoamericana, Vol. LXXVIII, Núms. 238-239,
ISSN 0034-9631 (Impreso)
} 
EL VIAJE

El título completo de Viaje maravilloso del Señor Nic-Nac... (ver arriba) indica muchos de los ingredientes claves del texto: el viaje fantástico de la ciencia-ficción temprana, un soupçon del Quijote y la utopía satírica, todos mezclados con las ciencias no siempre ortodoxas. ${ }^{6} \mathrm{Al}$ comenzar la obra, un narrador/editor cuenta que el señor Nic-Nac va anunciando por todo Buenos Aires que acaba de regresar del planeta Marte. Sus compatriotas lo encierran en un manicomio, aunque sólo después de consultar a dos autoridades científicas de la época: el psiquiatra José María Uriarte, primer director del hospital San Buenaventura (1863-76), y el astrónomo norteamericano Benjamin Gould (1824-96), primer director del Observatorio Astronómico de Córdoba (los dos son figuras reales). Nic-Nac resuelve publicar la crónica de su viaje como prueba de la verdad de su historia y de su propia cordura.

Nic-Nac cuenta que, con la ayuda de un espiritista alemán llamado Seele, ha descubierto cómo separar cuerpo de epíritu (privándose de comida), y ha mandado a su espíritu-imagen por el éter hasta Marte. Después de una disertación detallada, casi Verniana, sobre órbitas, diámetros planetarios y formas esferoides, el texto abandona los datos científicos para enfocarse en una "Martografía” inventada de la superficie del planeta (30). Nic-Nac mismo comienza a atar los cabos para el lector: "Por esta descripción se puede comprender fácilmente la analogía que existe entre el planeta Tierra y el planeta Marte. [. . . ] [E]n el hemisferio occidental las dos Nic-Naquias se asemejan á las dos Américas, y en el hemisferio oriental, en las mismas posiciones que Europa, Asia y Africa, se presentan Seélia, Protobia y Melania” (30-31). Luego de unos gestos coloniales superficiales - poner nombres en español a cosas marcianas y preguntar si los indígenas serán antropófagos- Nic-Nac se dirige al continente de Nic-Naquia. Cuando describe sus encuentros con los habitantes, o "Marcialitas", éstos parecen representar a veces miembros de una civilización más avanzada y otras veces ser dobles de los ciudadanos argentinos del siglo XIX. El aspecto analógico llega a predominar en la novela, aunque lo marciano como más adelantado que lo terrestre no desaparece del todo. Cuando finalmente descubrimos que el nombre del país que visita Nic-Nac es “Aureliana” está claro que la "plata” de “Argentina” tiene su elemento análogo en el “oro” de “Aureliana”, pero al mismo tiempo el oro es un metal más precioso que la plata.

Cuando publicó entregas semanales de las peripecias de Nic-Nac y de "las instituciones, costumbres y preocupaciones de[l] mundo desconocido" de Marte, Holmberg empleó su texto para comentar sobre asuntos locales pero también sobre temas candentes de interés internacional. Usó la sociedad marciana principalmente para

6 Examino la historia textual de Nic-Nac en "Back to the Future” y discuto el texto como viaje fantástico y utopía satírica en más detalle en "First Wave” y The Emergence of Latin American Science Fiction.

\begin{tabular}{l} 
Revista Iberoamericana, Vol. LXXVIII, Núms. 238-239, \\
\hline ISSN 0034-9631 (Impreso)
\end{tabular} 
satirizar a la suya, extrapolando y exagerando aspectos de la Argentina decimonónica al desplazarla a Marte. Los blancos más importantes de sus dardos son la situación política nacional, los debates sobre la religión y lo que consideraba la hipocresía religiosa de ciertos grupos, y la falta de contribuciones a la Argentina de unos científicos alemanes quienes no formaban la cantidad de discípulos argentinos esperada. ${ }^{7}$ La ciudad marciana donde Nic-Nac pasa la mayoría de su estadía se llama Theosophopolis, "ciudad de Dios y de los sábios”, y representa la ciudad argentina de Córdoba, sede del orden Jesuita en Argentina y de la, por entonces, recién fundada Academia Nacional de Ciencias donde los científicos alemanes, importados del Norte como Gould, investigaban en su torre de marfil (48). Nic-Nac también visita la capital de Aureliana, que está pasando por una situación de tensiones entre dos grupos de ciudadanos, para que Holmberg pueda transmitir a sus compatriotas su mensaje sobre la importancia de la unidad nacional frente a la situación política inestable después de las controvertidas elecciones presidenciales de 1874. El tema de dimensión internacional que más le preocupaba a Holmberg en Nic-Nac era la existencia de vida en otros planetas. La posibilidad de la existencia de otros mundos habitados ya era, como se discutirá más adelante, una cuestión muy debatida en los círculos científicos internacionales en 1875, aunque sólo llegó a su punto de mayor popularidad con la supuesta observación de Giovanni Schiaparelli de los canali en Marte en 1877-78.

En la película de Zaramella, Antonio es un niño de los años sesenta que adora los programas de ciencia-ficción de serie B de la era de la carrera espacial. Viaje a Marte abre de la forma siguiente:



7 Para más detalle sobre los asuntos locales ver Haywood Ferreira (Emergence 36-42), Ortiz (Transition) y Luis Holmberg 136-45.

$\begin{array}{llll}\text { ISSN 0034-9631 (Impreso) } & \text { ISSN 2154-4794 (Electrónico) }\end{array}$ 
Desde el comienzo del cortometraje, Zaramella usa la puesta en escena y el montaje para entretejer la realidad cotidiana y la realidad de la serie de televisión en la imaginación de Antonio y del público. Además de que el cortometraje y la serie de televisión comparten el mismo título y los mismos créditos iniciales, cuando el monstruo verde ruge, vemos la reacción en la cara de Antonio, quien está con el paisaje de Marte al fondo; cuando la madre de Antonio grita su nombre, el astronauta se distrae de su batalla-a-muerte con el monstruo. No está claro si el programa es argentino o importado, pero notamos que la lengua que se escucha en el inicio del corto en sí es el inglés, la primera de muchas referencias directas e indirectas al Norte en la obra. En este caso se evoca la centralidad del inglés para la industria cinematográfica y también para la ciencia-ficción.

Después de su programa, Antonio sale a jugar al explorador del espacio. Se encuentra con su abuelo y le dice que cuando sea grande se irá a Marte. Su abuelo responde, “¿Y para qué vamos a esperar? Yo te puedo llevar ahora”. Los dos suben a la grúa del abuelo y parten. Antonio está un poco decepcionado con la baja tecnología de su transporte, diciendo, "Abuelo, yo vi en la tele que iban en platillos voladores y en cohetes”, pero su abuelo le asegura: “Con grúa también se puede llegar. Vas a ver. Ésta es una camioneta especial”. Antonio se duerme en el camino. Cuando despierta ve un paisaje rojo con fantásticas formaciones de rocas; el abuelo le dice que han llegado a Marte. La música al fondo recuerda a "Also sprach Zarathustra” (Richard Strauss, 1864-1949), una referencia a 2001, Una odisea en el espacio (Stanley Kubrick, 1968), tal vez la película más icónica sobre viajes interplanetarios y la vida en otros planetas.

En la distancia Antonio descubre una estructura: es un quiosco muy familiar que vende comidas tan típicamente argentinas como las empanadas y las milanesas además de gasolina y recuerdos (la música ahora es un tango de Gardel que sale de la radio del quiosco). La mujer que allí trabaja tampoco se parece a los marcianos de la televisión (pero tampoco se parece físicamente a Antonio ni a sus compañeros de escuela). De hecho, con sus trenzas, su tez y pelo moreno y su ropa colorida, forma parte integral de lo que el material de prensa en inglés del corto llama "the folk approach" de la obra. Después de echar una mirada al abuelo, la mujer le confirma a Antonio que está en Marte y le dice "Bienvenido". El abuelo le compra algo que parece un casco espacial, y exploran el planeta "Marte", conduciendo la grúa por el terreno rojo y entre los arcos de piedra gigantes. A diferencia de la mayoría de los fans de la ciencia-ficción, Antonio tiene la oportunidad de vivir en carne propia el famoso sense of wonder.

Antonio cree durante varios años que ha estado en Marte. Pero una vez que llega a la escuela y les cuenta a sus compañeros que ha viajado al planeta rojo es desengañado públicamente. Parece probable que su abuelo, ahora muerto, le haya llevado a la región del Valle de la Luna en la provincia occidental de San Juan. La referencia al Valle de la Luna no se hace directamente en la película, pero el paisaje es reconocible para cualquier argentino. Zaramella confirma que el paisaje "marciano" del corto fue inspirado por el Valle de la Luna y por el cercano Parque Nacional Talampaya (Mensaje a la autora).

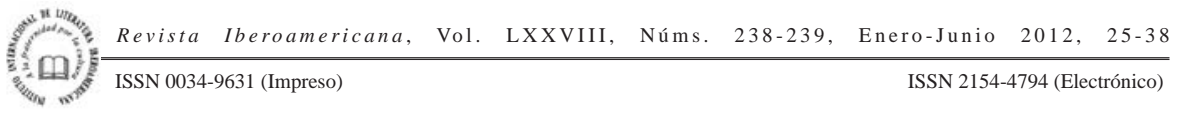


En entrevistas y en el material de prensa para Viaje a Marte Zaramella habla repetidamente de su "marco localista" (entrevista en Tea Imagen), pero enfatiza tal vez más la universalidad de la historia de un chico a quien la vida le obliga a dejar las cosas de niño. Zaramella también parece esquivarse algo de la etiqueta "ciencia-ficción” para su cortometraje. "The aim of Viaje a Marte", indica la versión inglesa del material de prensa, "is to give the audience a new perspective about life, taking as a starting point what can be taken at first sight as a science fiction story" (énfasis mío). No creo que con esta frase Zaramella esté negando los vínculos del corto con la ciencia-ficción, pues es evidente su entendimiento íntimo del género, desde los BEMs [bug-eyed monsters] hasta la retórica de la edad dorada de la ciencia-ficción ("Muere maldito monstruo invasor”). Parece, primero, que el conocimiento de Zaramella sobre la ciencia-ficción es algo que ha absorbido como parte integrante de su entorno sociocultural y, segundo, que la motivación principal al restar importancia al rótulo genérico es des-extrañar su película. Este acto de des-extrañar se debe no tanto al deseo de atraer un público mainstream sino porque la inspiración original para Viaje a Marte -la historia subyacente- fue autobiográfica y bastante terrestre. El co-guionista del corto, Mario Rulloni, había sido fanático de la serie norteamericana Route 66 (1960-1964) cuando era niño; su abuelo lo había "llevado" a "California” una tarde para ver la carretera "real” y Rulloni sólo descubrió la verdad años más tarde (contado en Jessen y García). Entonces, Zaramella-Rulloni están pensando en California y Holmberg está escribiendo antes de la explosión del furor sobre Marte en la imaginación popular ocasionado por Schiaparelli. La pregunta pendiente es: ¿por qué decidieron tanto en la Argentina de 1875 como en la de 2004 ubicar sus obras en el planeta rojo? ¿Por qué Marte?

\section{A MARTE}

El papel del planeta Marte en la imaginación humana ha sido moldeado por la ciencia y por la ciencia-ficción a lo largo de los siglos. Según Robert Markley, Marte ha funcionado como "una pantalla sobre la cual hemos proyectado nuestras esperanzas para el futuro y nuestros temores” para nuestro propio planeta (2). ${ }^{8} \mathrm{El}$ hecho de que Marte es el planeta con la superficie más perceptible desde la Tierra ha facilitado nuestro interés en el planeta rojo como objeto de observación. El surgimiento periódico de nuevas evidencias científicas de la presencia de agua en Marte ha contribuido a nuestras esperanzas de encontrar pruebas de vida más allá de nuestro propio orbe. Estos dos factores han cimentado a Marte como un destino prioritario para futuros viajes al espacio tanto en la realidad como en la ficción.

8 El libro de Markley, Dying Mars, traza la trayectoria de Marte en la realidad histórica y en la ficción. Ha sido muy útil para nuestros propósitos, aunque el estudio de Markley comienza con la ciencia-ficción escrita en el Norte después de 1880.

$\begin{array}{lllll}\text { ISSN 0034-9631 (Impreso) } & \text { ISSN 2154-4794 (Electrónico) }\end{array}$ 
La mayoría de la gente asocia la concientización popular de Marte y también la ciencia-ficción areocéntrica con la época del descubrimiento de los canali de Giovanni Schiaparelli (1835-1910) y con la subsiguiente popularización por Percival Lowell (1855-1916) de la interpretación de que estos “canales" fueron construidos por una civilización mucho más avanzada que la nuestra, una civilización que podría representar el futuro que nos esperaba. Fue en este clima científico-cultural que H.G. Wells (18661946) escribió La guerra de los mundos (1898) con su famosa invasión de la Tierra por los marcianos. Pero el viaje del señor Nic-Nac a Marte antecede todos estos eventos. Conviene recordar, por lo tanto, que el trabajo de Schiaparelli no representaba un cambio de rumbo tan radical para el campo de la areología. Ya para finales del siglo XVIII, indica Markley, la comunidad científica generalmente aceptaba que Marte poseía una ecología terrestre, y durante la década de 1860 tres científicos respetados en tres países diferentes declararon que habían encontrado evidencia de agua en Marte usando análisis espectrográfico (32, 53-54). Además, en 1862 el padre Pietro Angelo Secchi (1818-1878) había observado canali en la superficie de Marte (Fisher y Fisher 5-6, 26), y en ese mismo año Camille Flammarion (1842-1925) había publicado su La pluralité des mondes habités [La pluralidad de los mundos habitados]. En ese volumen Flammarion comparaba la Tierra y Marte, deduciendo que la probabilidad de la existencia de seres avanzados en Marte era alta (Markley 60, 391n17).

Los canali no entran en la "martografía" de Holmberg, pero él como investigador y como escritor estaba al tanto de los debates científicos y literarios sobre Marte. Holmberg reconoce dentro del texto mismo la influencia de Flammarion y de la ciencia europea en su Nic-Nac:

Espíritus brillantes como el de Flammarion sostienen hoy desde el corazón de la Europa [...] que los otros planetas son habitables, porque en ellos existen todas las condiciones esenciales para la evolucion de la vida, y aunque es verdad que no aseguran positivamente que otros hombres recorren sus tierras, admiten por lo menos la posibilidad de existencias análogas. (184)

También Lumen (1873), una obra literaria de Flammarion, desempeñó un papel clave en la composición de Nic-Nac. El viaje fantástico que no depende de un método de transporte extrapolado desde la tecnología moderna tiene una tradición larga en la cienciaficción y en la proto-ciencia-ficción (ver, por ejemplo, Nicolson, especialmente 40-41, 201-02). El papel del espiritismo en las dos obras y los paralelos entre la peregrinación del espíritu de Lumen por los planetas y la "transplanetación" de Nic-Nac indican que la novela de Flammarion fue la inspiración más importante para el método de viaje de nuestro primer héroe (Nic-Nac 24). ${ }^{9}$

9 Para una comparación más detallada entre Lumen y Nic-Nac, ver Haywood Ferreira, Emergence (38, 216 n. 17).

\begin{tabular}{l} 
Revista Iberoamericana, Vol. LXXVIII, Núms. 238-239, \\
\hline ISSN 0034-9631 (Impreso)
\end{tabular} 
Escribe Markley que, después de Schiaparelli, "Paradójicamente, Marte llega a ser tanto un mundo desfamiliarizado por sus diferencias con la Tierra como su casigemelo" (55). En este contexto específico Markley se refiere a semejanzas y diferencias de geografía y climatología, pero demuestra a lo largo de su libro que históricamente Marte también ha tenido una capacidad asombrosa para absorber proyecciones de conceptualizaciones opuestas de naturaleza biológica y social: Marte y los marcianos como lente para vislumbrar el futuro de nuestra especie y sociedad terrestres, pero también como ambiente exótico y "encarnación de [...] lo otro" (Markley 222). Es de notar que ya en 1875 Holmberg nos pinta un Marte paradójico dentro de una sola obra cuando, algo esquizofrenicamente, representa a los marcianos como miembros de una sociedad avanzada y utópica (el futuro que Holmberg anhelaba para los argentinos) y como argentinos desplazados (miembros de un presente argentino que Holmberg satirizaba como atrasado).

Después de La guerra de los mundos, el próximo hito en la ciencia-ficción marciana entre los viajes de Nic-Nac y de Antonio consiste en las novelas de Edgar Rice Burroughs, quien escribe bajo la influencia de las ideas Lowellianas en novelas como Una princesa de Marte (1912). La representación de marcianos avanzados, bélicos y/o decadentes persiste a mediados del siglo xx en objetos culturales influyentes tales como el personaje Marvin el Marciano de Looney Tunes (1948+) y la adaptación para la pantalla grande de La guerra de los mundos de Wells (1953; ganadora del Oscar para mejores efectos especiales en 1954). Aun a partir de los años sesenta cuando comenzaban a llegar las primeras fotografías de Marte desde las misiones de la NASA, la ciencia-ficción demuestra lo que Markley califica de "una nostalgia casi obsesiva para los mitos del Marte de Lowell” con la perduración de historias sobre artefactos dejados por desaparecidas razas tecnológicamente avanzadas o la terraformación y colonización de Marte (269, 288, 294). En el siglo xxi la búsqueda de vida en Marte no ha cesado, pero ahora se concentra en el nivel microscópico. "De ciertas manera”, escribe Kevin Zahnle en una explicación excelente de la vigencia perenne del planeta rojo, "el debate [sobre Marte y la posibilidad de vida allí] realmente ha cambiado muy poco desde los días de Flammarion y Lowell. La información más interesante queda en los límites de la resolución [...]. La vida en Marte siempre parece estar justo más allá de los campos que conocemos” (213). Hoy, cuando sabemos que no hay vida humanoide autóctona en Marte, la nostalgia por una civilización marciana se suele sustituir por la comprensión naciente y maravillada de que, para parafrasear a Ray Bradbury, la civilización avanzada en Marte ahora será ... la nuestra (Bradbury citado en Markley 270). De hecho, uno de los carteles actuales de reclutamiento para un programa de la NASA contiene la representación de trabajadores en un puesto de avanzada en Marte. ${ }^{10}$

${ }^{10}$ Uno de estos carteles está colgando en este momento en un tablero de anuncios para estudiantes en el $\begin{array}{lllll}\text { ISSN 0034-9631 (Impreso) } & \text { ISSN 2154-4794 (Electrónico) }\end{array}$ 
La nostalgia por el Marte romántico de Lowell se evoca claramente en Viaje a Marte en los gustos televisivos de Antonio niño. En la vida de Antonio adulto, en cambio, la imagen de los marcianos verdes y monstruosos se reemplaza por la aspiración por parte de algunos terrestres a la habitación humana de Marte. Cuando le pregunté a Zaramella cómo decidieron transponer la Ruta 66 a Marte, él respondió, "nos pareció un destino aún más fantástico e imposible” (Mensaje a la autora). Pero lo que es "fantástico” y fuera del alcance para un argentino -la Ruta 66, los cohetes, Marte- es alcanzable para los del Norte: en la segunda mitad de la película la humanidad llega a Marte.

\section{UN SEGUNDO VIAJE}

Cuando Antonio tiene cerca de cuarenta años y un hijo propio, su familia se junta alrededor de la televisón para ver la llegada de los astronautas norteamericanos a Marte. El locutor anuncia el “amartizaje” inminente [Las imágenes que acompañan la emisión se describen entre corchetes]:

¡Un nuevo hito en la historia de la Humanidad! Otro salto gigante desde que el Hombre puso por primera vez un pie en la Luna. Porque hoy cuatro embajadores de nuestro planeta llegarán a Marte [Cámara recorre grupo de space jockeys de cuello ancho, frente estrecha y mirada algo vacía]. Esta misión fue concebida por hombres que querían llegar más allá. Tras cinco años de intenso entrenamiento y luego de una rigurosa selección [Clip de astronautas bajando un tobogán de patio de recreo en sus trajes espaciales], los astronautas han adaptado sus costumbres y pueden convivir en la nave y dedicarse de lleno a complejas y delicadas tareas científicas [En una simulación de la nave espacial un astronauta, con la lengua para fuera, lee una revista con una chica semi-desnuda en la portada; dos otros, con tutús rosados encima de sus trajes espaciales, usan la gravedad nula para el ballet sincronizado].

A pesar del empleo de términos inclusionistas como "la Humanidad", "el Hombre" y "nuestro planeta", es la NASA/el Norte que manda el cohete y las personas a Marte. Y, a pesar de la retórica estándar del locutor para una misión espacial y de su perfeccionamiento del tono grave-pero-emocionado apropiado para la importancia del evento, las imágenes que muestra Zaramella -el tobogán, la revista pornográfica, los tutús, los astronautas bobos realizando simples y fútiles tareas- no apoyan, sino que subvierten la supuesta representación tradicional del Norte como terreno de la ciencia y la tecnología. Las imágenes se burlan hasta de la afirmación de que los representantes de la nueva potencia colonizadora interplanetaria "han adaptado sus costumbres", de hecho,

departamento de ingeniería aeroespacial en Iowa State University. También se encuentra en el website incluído en la bibliografía bajo la entrada "Mars".

$\begin{array}{lllll}\text { ISSN 0034-9631 (Impreso) } & \text { ISSN 2154-4794 (Electrónico) }\end{array}$ 
han mantenido sus costumbres de siempre, adaptándolas solamente a las condiciones de ingravidez de su nave.

El aún desilusionado Antonio ni siquiera podrá ver la emisión en directo de la llegada a Marte, ya que recibe una llamada para su servicio de grúa. Él sube a la vieja camioneta que había pertenecido a su abuelo. Se dirige a la zona aislada que había indicado el cliente, manteniéndose en contacto con éste por teléfono, pero no encuentra el auto averiado. Anochece, y Antonio está cada vez más perdido. Finalmente la pantalla de su teléfono celular registra "no signal” en el inglés nativo de la máquina. Cuando Antonio se distrae intentando hacerlo funcionar, él mismo tiene un accidente. La grúa se sale del camino. Antonio se da un golpe en la cabeza contra el volante. Él se recupera rápidamente, pero la grúa no. Entonces, decide ir en busca de auxilio. Camina hasta el amanecer y llega a un paisaje extrañamente familiar: la tierra roja, las fantásticas formaciones de rocas ... pero esta vez cuando ve el quiosco con la misma señora, ahora de trenzas grises, no pregunta si está en Marte. El tango argentino tocando en la radio es interrumpido por un ruido creciente y todo comienza a temblar. ${ }^{11}$

Aterriza una nave espacial y bajan los astronautas rigurosamente seleccionados por los norteamericanos [se escuchan otra vez unas barras de música con timbales tipo "Also sprach Zarathustra”]. Están atónitos, como estaría cualquier persona del siglo xxi al encontrar vida sensible en Marte. "Bienvenidos", les dice la mujer con el tono impávido que usa para recibir a los recién llegados de todas partes. La falta de sorpresa demostrada por la mujer se deberá a la gama de reacciones que habrá visto en sus décadas trabajando en un lugar fantástico. Pero también es una referencia a que la situación es una repetición de eventos históricos, del encuentro original entre exploradores foráneos y los autóctonos del Nuevo Mundo (una situación matriz importante para historias de "primer contacto" en la ciencia-ficción). La apariencia "folk" de la mujer contribuye a marcar esta alusión al primer "primer contacto" con los europeos y a sugerir además el papel análogo de los Estados Unidos para la América Latina hoy.

Antonio, sonriendo, también comienza a saludar con la mano, y ésta es la imagen que las cámaras del cohete transmiten a la televisión para el reportaje titulado "Breaking News: Vida en Marte”. [La música al fondo cambia a una composición original de Zaramella y Germán Castro; predominan las guitarras acústicas. Sigue hasta el final.] La primera transmisión de audio de los astronautas es: "Houston, we have a problem”. Durante los créditos finales aparecen los dibujos de Antonio niño de la grúa de su abuelo despegando de la tierra, de Antonio luchando con el monstruo verde de su serie, del

${ }^{11}$ El tango, esta vez, es "Volver" (música: Carlos Gardel; letra: Alfredo Le Pera). Se escuchan los versos siguientes, muy apropiados para describir los viajes y la vida de Antonio: "Tengo miedo de las noches/ que pobladas de recuerdos/encadenen mi soñar./Pero el viajero que huye/tarde o temprano/detiene su andar./Y aunque el olvido/que todo destruye/haya matado mi vieja ilusión,/guardo escondida/una esperanza humilde...”.

Revista Iberoamericana, Vol. LXXVIII, Núms. 238-239,
ISSN 0034-9631 (Impreso) 
casco que le compró el abuelo como recuerdo de su primer viaje a este lugar. Después de los créditos vemos a Antonio adulto tomando mate mientras los astronautas comen empanadas y beben vino. "Delicious", dicen los astronautas.

\section{¿A MARTE?}

Tanto Nic-Nac como Viaje a Marte nos dejan con la duda de si el viaje realmente ocurrió. Ambas obras de ciencia-ficción tienen también tendencias fantásticas. Están llenas de recursos de vacilación todorovianos: ¿Nic-Nac estaráloco? ¿Puede el espiritismo -aunque tenga patrocinio alemán-realmente funcionar como método de transporte para un viaje espacial? O ¿̇será el viaje de Nic-Nac el resultado de alucinaciones provocadas por la inanición? En el primer viaje a Marte del cortometraje Antonio es un testigo intrínsecamente indigno de confianza por su juventud, pero también porque se duerme durante el viaje sugiriendo la posibilidad de la percepción afectada por el sueño. En el segundo viaje, Antonio adulto se pierde y hasta pierde la señal de su teléfono celular y, además, recibe un golpe en la cabeza después de conducir toda la noche.

Ambas obras intentan abarcar interpretaciones racionales y también sobrenaturales de los eventos con sus finales abiertos. El narrador de Nic-Nac le dice al lector que NicNac sufre de una rara forma de demencia llamada "Manía planetaria”, que los médicos dicen que es "un tanto instruido, al que se le pueden creer muchas cosas que dice, exceptuando, empero, los medios de que se ha valido para transmigrar de la Tierra á Marte, y de este á aquella” (186-87). Al concluir la novela, el narrador deja sin resolver el tema de la cordura/locura de Nic-Nac y el de la realidad de los eventos específicos que decía haber presenciado en Marte, pero rescata con punto y detalle las ideas de Nic-Nac en lo que se refiere a la vida en otros mundos. Cita a la autoridad de "espíritus brillantes como el de Flammarion" y declara: "La pluralidad de los mundos habitados no es una fantasía nacida en un cerebro calenturiento, es una necesidad, una conquista del espíritu humano, un homenaje á la grandeza del Universo” (184-85).

En el corto de Zaramella el espectador está convencido durante la mayor parte de la película que el viaje a Marte fue una decepción bastante inocente llevada a cabo por un abuelo benévolo. El episodio en la escuela deja en Antonio el mensaje de que sólo puede aspirar a conducir una grúa que al fin y al cabo no es tan especial, y nunca a pilotear una nave espacial. Los norteamericanos serán astronautas e irán a Marte, él no. Incluso cuando él llegue a Marte por segunda vez lo pensamos entre comillas: "Marte”. Pero entonces llega el cohete de la NASA y, cuando abre la puerta, los astronautas del Norte descubren que no son los primeros humanos a llegar a Marte: los habitantes les saludan en español y la cuisine local es argentina. Aún cuando la última -así como la primera- línea de la película estén en inglés en lo que es ahora un reconocimiento claro de la influencia del Norte en la ciencia y la ciencia-ficción, Zaramella recontextualiza

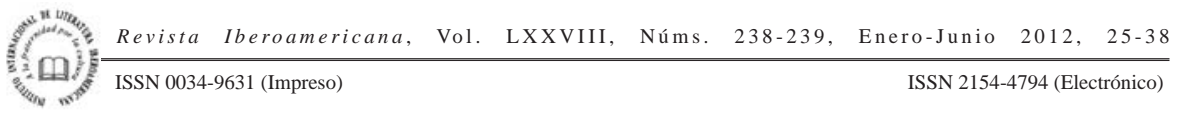


esa línea (como buen antropófago en la tradición de Oswald de Andrade). Cuando los astronautas bajan de la nave esperamos una nueva versión de "One small step for man...”, pero en su lugar escuchamos la reiteración de otra frase famosa, aunque menos auspiciosa, "Houston, we have a problem”. ¿ Será el problema otro error de un colonizador potencial como aquella equivocación que llevó a Colón a encontrar el Nuevo Mundo? ¿Estos Colones del siglo xxi habrán llegado al Valle de la Luna, un destino errado, otra vez? ¿O de algún modo estarán en Marte mismo? De todas formas, en este un-comingof-age story, Antonio ha recuperado su perdido sense of wonder.

En la novela y en el cortometraje, Marte es la Tierra ... pero Marte también es Marte. Al llegar a Marte en cada obra, al principio los marcianos funcionan como un espejo por lo menos tanto como un "otro", hasta que finalmente, al final de Viaje a Marte, se llega a una comprensión simultánea y paradójica de que lo argentino es lo otro y que el centro de la ciencia y de la ciencia-ficción tal vez no esté donde los del Norte-y los del Sur-se lo han figurado. Tanto si los protagonistas son genios o sufren de "Manía planetaria", si siguen apareciendo en el mismo quiosco turístico en un parque nacional o si de alguna manera han descubierto un atajo a Marte en una grúa verdaderamente "especial", estas dos obras demuestran la presencia de Marte en la ciencia-ficción latinoamericana y en el imaginario latinoamericano desde los primeros días del género hasta el presente. Y, pese a su representación del papel central de las naciones del Norte en los viajes espaciales, en ambas historias Holmberg y ZaramellaRulloni nos dejan con la certeza -o por lo menos la convicción- de que un argentino ha sido el primer ser humano en pisar la superficie del planeta rojo y que hay más de una ruta para viajar a Marte.

\section{BiBLIOGRAFÍA}

Aparisi, María Cinta, José A. Blanco y Marcie D. Rinka. Revista: Conversación sin barreras. $2^{\mathrm{a}}$ ed. Boston: Vista Higher Learning, 2007.

Capanna, Pablo. El mundo de la ciencia ficción: Sentido e historia. Buenos Aires: Letra Buena, 1992.

Fisher, David E. y Marshall Fisher. Strangers in the Night: A Brief History of Life on Other Worlds. Washington, D.C.: Counterpoint, 1998.

García, María Eugenia. "Zaramella se anima”. La Nación 14 abril 2005. <http://www. zaramella.com.ar/jpz_online/articulos/la-nacion1.html>. 24 agosto 2009.

Haywood Ferreira, Rachel. "Back to the Future: The Expanding Field of Latin-American Science Fiction.” Hispania 91/2 (2008): 352-62.

The Emergence of Latin American Science Fiction. The Wesleyan Early Classics of Science Fiction. Middletown, CT: Wesleyan UP, 2011.

$\begin{array}{lllll}\text { ISSN 0034-9631 (Impreso) } & \text { ISSN 2154-4794 (Electrónico) }\end{array}$ 
“The First Wave: Latin American Science Fiction Discovers Its Roots.” Science Fiction Studies 34/3 (2007): 432-62.

Holmberg, Eduardo Ladislao. "Viaje maravilloso del señor Nic-Nac [selecciones]”. Los argentinos en la luna. 1875-76. Eduardo Goligorsky, ed. Buenos Aires: Ediciones de la Flor, 1968. 15-31.

Viaje maravilloso del señor Nic-Nac al planeta Marte. 1875-76. Pablo Crash Solomonoff, ed. Buenos Aires: Ediciones Colihue, 2006.

Viaje maravilloso del señor Nic-Nac en el que se refieren las prodijiosas aventuras de este señor y se dan á conocer las instituciones, costumbres y preocupaciones de un mundo desconocido: Fantasía espiritista. Buenos Aires: El Nacional, 1875.

"Viaje maravilloso del señor Nic-Nac en el que se refieren las prodijiosas aventuras de este señor y se dan á conocer las instituciones, costumbres y preocupaciones de un mundo desconocido: Fantasía espiritista”. El Nacional 29 nov. 1875 al 13 mar.1876. Folletín del Lunes.

Holmberg, Luis. Holmberg el último enciclopedista. Buenos Aires: Colombo, 1952.

Iribarren, María. “Tengo más ídolos en el cine que en la animación”. Entrevista a Juan Pablo Zaramella. Cinecrópolis. Julio 2005. <http://www.cinceropolis.com/ entrevistas/jpzaramella.htm>. 24 agosto 2009.

Jessen, Taylor. "Fresh from the Festivals: September 2005's Reviews.” Animation World Magazine 28 septiembre 2005. Web. 24 agosto 2009.

Markley, Robert. Dying Planet: Mars in Science and the Imagination. Durham: Duke UP, 2005.

Mars. NASA Undergraduate Student Research Program. 2008. <http://usrp.usra.edu/ multimedia/mars2008.pdf>. 20 mayo 2010.

Nicolson, Marjorie Hope. Voyages to the Moon. New York: Macmillan Company, 1948.

Ortiz, Eduardo L. "On the Transition from Realism to the Fantastic in the Argentine Literature of the 1870s: Holmberg and the Córdoba Six.” Science and the Creative Imagination in Latin America. Evelyn Fishburn y Eduardo L. Ortiz, eds. Londres: Institute for the Study of the Americas, 2005. 59-85.

Todorov, Tzvetan. The Fantastic: A Structural Approach to a Literary Genre. Richard Howard, trad. Ithaca: Cornell UP, 1973.

Viaje a Marte. Dir. Juan Pablo Zaramella. Guión Mario Rulloni y Juan Pablo Zaramella. JPZtudio, 2004. Cortometraje.

Zahnle, Kevin. "Decline and Fall of the Martian Empire.” Nature 412 (2001): 209-13.

Zaramella, Juan Pablo. “Como soy argentino... Juan Pablo Zaramella.” Instinto Guapo. 4 abril 2008. <http://www.instintoguapo.com/2008/04/como-soy-argentino-juanpablo-zaramella.html>. 24 agosto 2009.

"El hombre plastilina". Entrevista con Sandra Commisso. Clarín. Clarín, 22 dic. 2004. <http://www.clarin.com/diario/2004/12/22/espectaculos/c-00301.htm>. 24 agosto 2009.

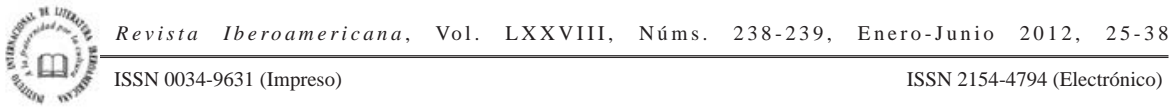


“Entrevista a Juan Pablo Zaramella, realizador de 'Viaje a Marte', el corto argentino más premiado del año”. Tea Imagen - Gacetilla. <http://www.zaramella. com.ar/jpz_online/articulos/tea.html>. 24 agosto 2009.

“Material de prensa”. Viaje a Marte. Juan Pablo Zaramella. <http://www. viajeamarte.com.ar/homeEsp.htm>. 20 mayo 2010

Mensaje a la autora. 31 agosto 2009. E-mail.

"Press Kit.” Journey to Mars. Juan Pablo Zaramella. <http://www.viajeamarte. com.ar/inlges/homeIng.htm>. 20 mayo 2010. $\begin{array}{lllrl}\text { Revista Iberoamericana, Vol. LXXVIII, Núms. 238-239, } & \text { Enero-Junio 2012, 25-38 } \\ \text { ISSN 0034-9631 (Impreso) } & \text { ISSN 2154-4794 (Electrónico) }\end{array}$ 